REVISTA DE GEOCIÊNCIAS DO NORDESTE

Northeast Geosciences Journal

v. $6, \mathrm{n}^{\circ} 2(2020)$

https://doi.org/10.21680/2447-3359.2020v6n2ID19406

ISSN: 2447-3359

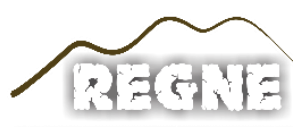

\title{
PETROGRAFIA E LITOQUÍMICA DAS ROCHAS MIGMATÍTICAS DA PORÇÃO NORTE DO CINTURÃO SALVADOR-ESPLANADA- BOQUIM, CRÁTON DO SÃO FRANCISCO, BRASIL
}

\section{Marcus Vinicius Costa Almeida Junior ${ }^{1}$; Angela Beatriz de Menezes Leal'² Johildo Salomão Figuerêdo Barbosa ${ }^{3}$; Moacyr Moura Marinho ${ }^{4}$}

${ }^{1}$ Mestre em Geologia, Programa de Pós-Graduação em Geologia, Núcleo de Geologia Básica (NGB), Instituto de Geociências, Universidade Federal da Bahia (UFBA), Salvador-BA, Brasil. ORCID: https://orcid.org/0000-0002-2742-5290

Email: mvcajr@gmail.com

${ }^{2}$ Doutora em Geologia, Programa de Pós-Graduação em Geologia, Núcleo de Geologia Básica (NGB), Instituto de Geociências, Universidade Federal da Bahia (UFBA), SalvadorBA, Brasil.

ORCID: https://orcid.org/0000-0003-1179-9877

Email: angelab@ufba.br

${ }^{3}$ Doutor em Geologia, Programa de Pós-Graduação em Geologia, Núcleo de Geologia Básica (NGB), Instituto de Geociências, Universidade Federal da Bahia (UFBA), Salvador-BA, Brasil. ORCID: https://orcid.org/0000-0002-2277-1522

Email: johildo.barbosa@gmail.com

${ }^{4}$ Doutor em Geologia, Programa de Pós-Graduação em Geologia, Núcleo de Geologia Básica (NGB), Instituto de Geociências, Universidade Federal da Bahia (UFBA), Salvador-BA, Brasil. ORCID: https://orcid.org/0000-0002-2143-5594

Email:mmm@ufba.br

\section{Resumo}

A área de estudo localiza-se na porção extremo norte do Cinturão Salvador-Esplanada-Boquim, nas porções sul do estado de Sergipe e nordeste do estado da Bahia, Brasil. Este Cinturão apresenta três faixas litológicas de rochas metamórficas denominadas Complexo Migmatítico Rio Real-Riachão do Dantas (CMRR), Complexo Granulítico Esplanada-Boquim (CGEB) e Complexo Gnáissico/Migmatítico-Granulítico Costa Atlântica (CGGCA). Esse artigo se restringe aos estudos petrológicos da primeira faixa de migmatitos que foi subdividida em Ortognaisse Migmatítico Granítico Leste (OMGL) e Ortognaisse Migmatítico Granítico Oeste (OMGO). Ambas, macroscopicamente e petrograficamente são similares, cujas paragêneses minerais indicam a ocorrência de processos metamórficos de médio grau, da fácies anfibolito com faixas retrometamórficas. Litoquimicamente, notou-se características particulares das porções claras e escuras de cada um desses tipos de migmatitos e que, embora tenham sofrido migmatização, mantiveram as características dos protólitos, permitindo identificar as porções félsicas como provenientes de magma variando entre cálcio-alcalino normal a cálcio-alcalino de alto $\mathrm{K}$.

Palavras-chave: Cinturão Salvador-Esplanada-Boquim; Litquímica; Petrografia.

\section{PETROGRAPHY AND LITHOCHEMISTRY FROM MIGMATITIC ROCKS OF NORTH PORTION OF THE SALVADOR-ESPLANADA-BOQUIM BELT, SÃO FRANCISCO CRATON, BRAZIL}

\section{Abstract}

The study area is located in the extreme northern of the SalvadorEsplanada-Boquim Belt, in the southern portions of the state of Sergipe and northeastern state of Bahia, Brazil. This belt has three lithological groups of metamorphic rocks called Rio RealRiachão do Dantas Migmatitic Complex (CMRR), EsplanadaBoquim Granulitic Complex (CGEB) and Gneissic/GranuliticMigmatitic Atlantic Coast Complex (CGGCA). This article is limited to the petrological study of the first migmatites group that has been subdivided into East Granitic Migmatitic Orthogneisses (OMGL) and WestGranitic Migmatitic Orthogneiss (OMGO). Both, macroscopically and petrographically are similar, whose mineral parageneses indicate the occurrence of metamorphic processes of medium grade, from the amphibolite facies with retrometamórficas tracks. Lithochemically, it was noted particular characteristics of light and dark portions from these types of migmatites and that, although they have suffered migmatisation, kept also the characteristics of the protolith, allowing identify the felsic portions as from magma ranging from calc-alkaline regular to calcium-alkaline of the high $\mathrm{K}$.

Keywords: Salvador-Esplanada-Boquim Belt, Lithochemistry, Petrography. 


\section{PETROGRAFÍA Y LITOQUÍMICA DE LAS ROCAS MIGMÁTICAS DE LA PORCIÓN NORTE DEL CINTURÓN SALVADOR-ESPLANADA-BOQUIM, CRATON DEL SÃO FRANCISCO, BRASIL}

\section{Resumen}

El área de estudio se encuentra en el extremo norte del Cinturón Salvador-Esplanada-Boquim, en las partes meridionales del estado de Sergipe y el estado nororiental de Bahía, Brasil. Este cinturón tiene tres grupos litológicos de rocas metamórficas llamadas Complejo Migmatítico Rio Real-Riachão do Dantas (CMRR), Complejo Granulítico Esplanada-Boquim (CGEB) y Complejo Gneissico / Granulítico-Migmatítico de la Costa Atlántica (CGGCA). Este artículo se limita al estudio petrológico del primer grupo de migmatitas que se ha subdividido en Ortogneises Migmatíticos Graníticos Este (OMGL) y Ortogneis Migmatíticos Migratorios Oeste (OMGO). Ambos, macroscópicamente y petrográficamente son similares, cuyas paragénesis mineral indican la ocurrencia de procesos metamórficos de grado medio, a partir de las facies de anfibolitos con pistas retrometamórficas. Litoquímicamente, se observaron características particulares de las porciones claras y oscuras de estos tipos de migmatitas y que, aunque han sufrido migmatización, mantuvieron también las características del protolito, lo que permitió identificar las porciones felsicas como del magma que van desde el calcio alcalino regular al calcio alcalino de la alta $\mathrm{K}$.

Palabras-clave: Cinturón Salvador-Esplanada-Boquim, Litoquímica, Petrografía.

\section{INTRODUÇÃO}

O Cráton do São Francisco (CSF) é constituído de terrenos gnáissicos, graníticos de natureza granulítica e migmatítica com idades variando do Arqueano ao Paleoproterozoico, sobrepostos por uma cobertura paraplataformal de idade Meso a Neoproterozoica (BARBOSA et al., 2012). Sua história geológica se dá a partir de eventos tectônicos, magmáticos e metamórficos, além de eventos erosivos e de exumação, sendo assim caracterizado por uma amplo contexto evolutivo, correspondendo a um dos melhores e mais completos registros geológicos do Precambriano brasileiro (HASUI, 2013) (Figura 01).

No limite setentrional desse cráton, afloram as rochas pertencentes ao Cinturão Salvador-Esplanada-Boquim (CSEB), constituído por ortognaisses de composição variada, reequilibrados nas fácies granulito e anfibolito, além de rochas calciossilicáticas, quartzitos, intrusões de granitoides e corpos máficos a ultramáficos (BARBOSA, 1990; SANTOS et al., 2001; OLIVEIRA, 2014).

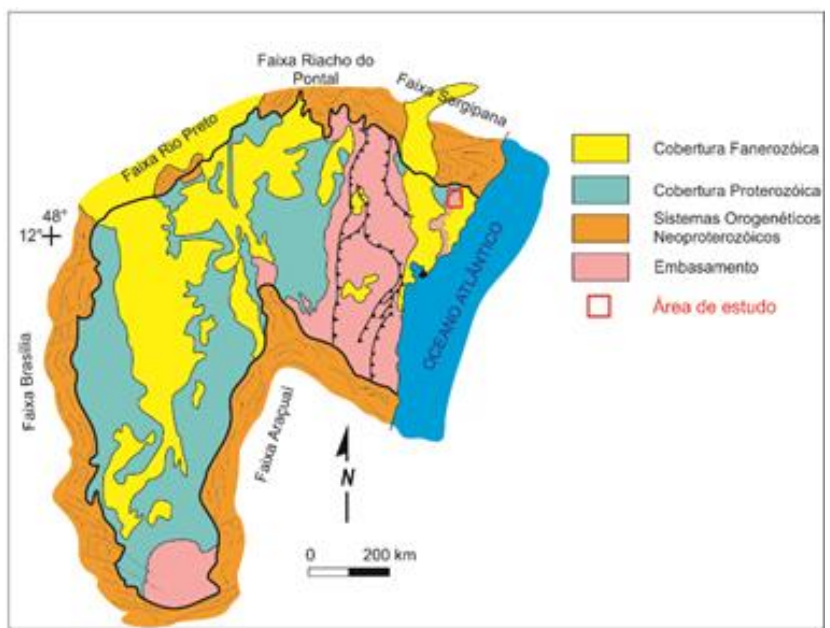

Figura 01 - Cráton do São Francisco, com delimitação da área de estudo. (Modificado de Alkmim et al., 1993)

O CSEB refere-se a um conjunto de rochas arqueanopaleoproterozoicas, metamorfisadas em alto grau, ocorrendo desde a margem leste da bacia sedimentar do Recôncavo-TucanoJatobá, representada litologicamente por três faixas de rochas metamórficas relativamente contínuas, delimitadas por falhas de empurrão e/ou zonas de cisalhamentos com planos transcorrentes, que produziu estruturação de direção NNE (SANTOS et al., 2001; OLIVEIRA, 2014). Esses cisalhamentos possuem expressão regional e profundas, registradas pela geofísica (OLIVEIRA JR., 1990; SANTOS et al., 2001; SILVA et al., 2002; BARBOSA et al., 2012; BARBOSA et al., 2018): (i) a primeira faixa, situada a oeste, denominada de Complexo Migmatítico Rio Real-Riachão do Dantas (CMRR), se estende desde o sul de Aporá até Riachão do Dantas, ao norte, possuindo ortognaisses migmatíticos com estruturas dobradas, schlieren e estromática e granitoides, além da Suíte Granitoide Teotônio-Pela Porco; (ii) a segunda, situada na parte central, denominada Complexo Granulítico EsplanadaBoquim (CGEB), se estende desde Esplanada até Boquim, contendo granulitos com encraves básicos, níveis de kinzigitos e lentes de quartzitos subordinados e, (iii) a terceira, situada a leste, denominada Complexo Gnaissico/Migmatítico-Granulítico Costa Atlântica (CGGCA), que se distribui desde as imediações da cidade de Conde estendendo-se em direção ao norte até a Costa Atlântica, tendo como destaque litologias do tipo ortognaisses bimodais, por vezes migmatizados, com termos félsicos tonalíticos-granodioríticos e máficos, não excluindo a presença de intrusões sieno-monzograníticas e núcleos granulíticos. Tanto a primeira como a segunda faixa são atravessadas por diques fissurais ácidos a intermediários, esses últimos constituindo os diques de Arauá (SANTOS et al., 2001; D'EL-REY SILVA, 2005). Essas litologias, sobretudo aquelas da segunda e terceira faixas, estão superpostas pelos sedimentos do Grupo Barreiras. Salienta-se que este estudo priorizou as rochas migmatíticas da primeira faixa (CMRR).

A área de estudo localiza-se no extremo norte do CSEB e teve por objetivo caracterizar as rochas gnaissicas-migmatíticas de médio a alto grau deste cinturão, levando-se em consideração 
aspectos petrográficos e litoquímicos e mantendo a divisão proposta por Barbosa et al. (2018).

\section{METODOLOGIA}

Para as análises petrográficas, as lâminas foram confeccionadas no Laboratório de Petrografia da CPRM Companhia de Pesquisa e Recursos Minerais, em Salvador, Bahia, além da adição de lâminas provenientes do Projeto GEOTERM-NE (2010).

Para os estudos litoquímicos foram selecionadas 49 amostras, sendo 13 provenientes dos trabalhos de campo realizados durante a pesquisa e 36 provenientes do Projeto GEOTERM-NE (2010); todas analisadas no laboratório da GEOSOL - Geologia e Sondagens Ltda, por meio dos métodos de fusão com metaborato de lítio (ICP-OES e ICP-MS). Pelo método ICP-OES, determinou-se os teores de $\mathrm{SiO}_{2}, \mathrm{TiO}_{2}, \mathrm{Al}_{2} \mathrm{O}_{3}, \mathrm{Fe}_{2} \mathrm{O}_{3}, \mathrm{MnO}$, $\mathrm{MgO}, \mathrm{CaO}, \mathrm{Na}_{2} \mathrm{O}, \mathrm{K}_{2} \mathrm{O}, \mathrm{P}_{2} \mathrm{O}_{5}, \mathrm{Cr}_{2} \mathrm{O}_{3}$, além dos elementos $\mathrm{Ba}, \mathrm{Sr}$, $\mathrm{Y}, \mathrm{Zr}$, V sendo os primeiros em porcentagem de peso e os últimos em ppm. Pelo método ICP-MS foram determinados os elementos $\mathrm{Ce}, \mathrm{Cs}, \mathrm{Dy}, \mathrm{Er}, \mathrm{Eu}, \mathrm{Gd}, \mathrm{Hf}, \mathrm{Ho}, \mathrm{La}, \mathrm{Lu}, \mathrm{Nb}, \mathrm{Nd}, \mathrm{Ni}, \mathrm{Pr}, \mathrm{Rb}, \mathrm{Sm}$, $\mathrm{Ta}, \mathrm{Tb}, \mathrm{Th}, \mathrm{Tm}, \mathrm{U}$, e Yb, todos em ppm. Foram ainda calculados, também em ppm, os valores de K, P e Ti, a partir dos teores dos seus óxidos. A perda ao fogo foi calculada pela diferença de peso após aquecer $0,2 \mathrm{~g}$ de amostra a $1000^{\circ} \mathrm{C}$ e o erro analítico é menor que $5 \%$ para óxidos e do que $2 \%$ para os elementos traços.

\section{RESULTADOS E DISCUSSÃO}

\subsection{Aspectos Macro e Microscópicos}

Como pode ser observado na figura 02, no Complexo Migmatítico Rio Real-Riachão do Dantas (CMRR) do CSEB, na área de estudo, ocorrem basicamente dois tipos de migmatitos: na porção leste, em contato com o Complexo Granulítico EsplanadaBoquim (CGEB), situa-se o Ortognaisse Migmatítico Granítico Leste (OMGL) e a oeste situa-se o Ortognaisse Migmatítico Granítico Oeste (OMGO).

\subsubsection{Ortognaisse Migmatítico Granítico Leste (OMGL)}

Corresponde a rochas graníticas-gnáissicas, de granulometria média a grossa, coloração acinzentada, com variações de tons em decorrência da maior ou menor quantidade do mineral biotita, além de bandamento composicional, característico dessa unidade (Figura 03A). A ocorrência de bolsões de leucossoma inclusos no paleossoma é observado, além de todo o conjunto ser afetado por deformação dúctil (Figura 03B). Ocorrência também de veios leucossomáticos, compostos principalmente de quartzo e feldspatos, bem como pequenas porções graníticas apresentando contato difuso com a encaixante, sendo possivelmente ação de processo anatético. Observa-se também nessa faixa migmatítica a presença de ortognaisses de composição granítica com porções incipientes de migmatização.

Petrograficamente (Figuras 03C e 03D), apresenta principalmente microestruturas inequigranular e granoblástica granular e, secundariamente, microestruturas granoblástica poligonal, poiquiloblástica do tipo peneira e lepidoblástica. Identifica-se também a presença da textura mimerquítica, com intercrescimento de quartzo e plagioclásio, além de pertitas e mesopertitas, em proporções variáveis. Nas amostras coletadas próxima à zona de cisalhamento Aporá-Itamira que separa o CMRR do CGEB (Figura 02), foi possível observar uma microestrutura granolepidoblástica e porfiroclastos de quartzo e feldspatos imersos em uma matriz composta de biotita, quartzo, plagioclásio e microclínio. Ainda foi possível notar veios quartzofeldspáticos representando o leucossoma dessa unidade. Em termos modais são constituídas por quartzo (30-45\%), plagioclásio (20-30\%), biotita (8-20\%), microclínio (5-15\%), muscovita (2-10\%), clorita (2-7\%), hornblenda (2-4\%), opacos (1-5\%), além de epidoto, magnetita, hematita e zircão como minerais acessórios, sendo classificadas como sieno a monzogranitos, com maior tendência ao segundo, de acordo com o diagrama QAP de Streckeisen (1976) (Figura 05).

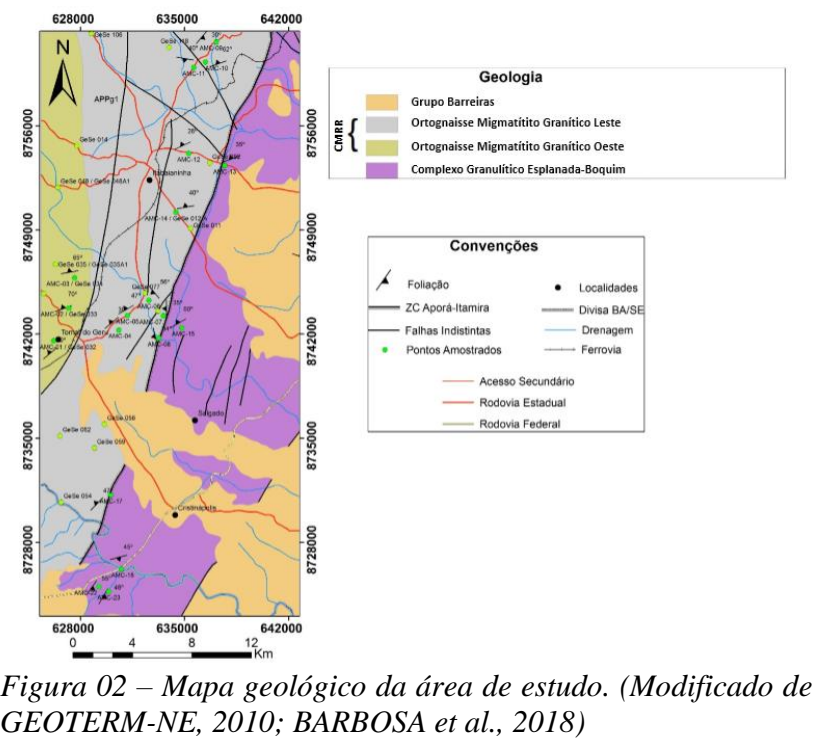

3.1.2. Ortognaisse Migmatítico Granítico Oeste (OMGO)

São migmatitos ortoderivados de composição granítica, apresentando feições migmatizadas bem evidenciadas em diversos estágios de fusão parcial, desde metatexitos com bandamento bem marcado a diatexitos nebulíticos, além da ocorrência de bolsões leucossomáticos pegmatoides, compostos basicamente por quartzo e feldspatos (Figuras 04A e 04B). Hierarquizou-se o mesossoma como uma rocha gnáissica de coloração acinzentada, foliação bem marcada e granulometria média; o neossoma foi considerado como sendo representativo da fase melanossomática, rica em biotita. Há, ainda, ocorrências de porções mais homogêneas, sugerindo tratar-se do protólito plutônico da rocha.

Petrograficamente (Figuras 04C e 04D), apresentam micorestruturas inequigranular e granoblástica granular, além de granoblástica poligonal e poiquiloblástica tipo peneira. A microestrutura lepidoblástica ocorre em menor proporção, bem como as mimerquítica e pertítica. Seus constituintes mineralógicos são compostos por quartzo (30-35\%), ortoclásio (20-25\%), plagioclásio (12-20\%), microclínio (7-15\%), biotita 
(3-15\%), muscovita (3-9\%), clorita (2-10\%), magnetita (1\%), hematita $(1 \%)$ e opacos (2-5\%), além do zircão como traço. Foram classificadas como predominantemente sienograníticas, com poucas amostras tendendo a monzograníticas, de acordo com o diagrama QAP de Streckeisen (1976) (Figura 05).

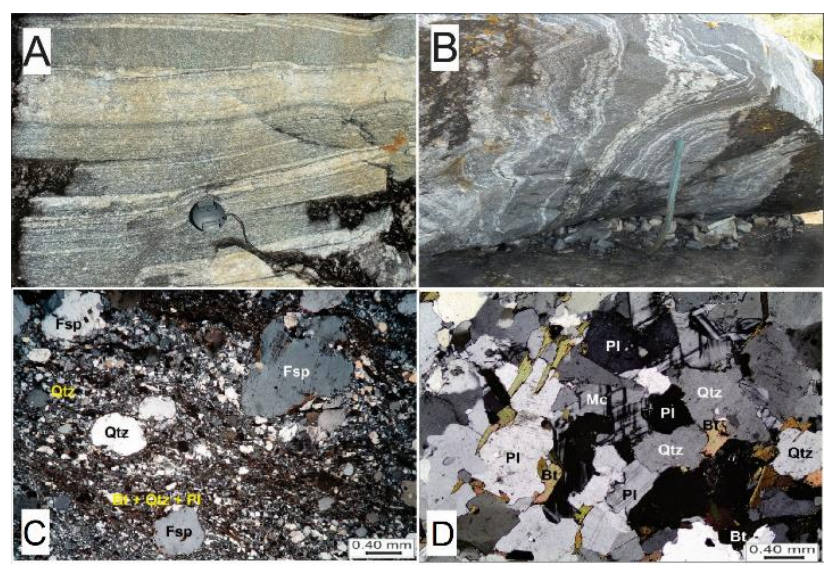

Figura 03 - Feições de campo e fotomicrografias do OMGL. (A) Bandamento composicional; (B) Presença de leucossoma estromático em rocha com processo de migmatização; (C) Aspecto geral da microestrutura porfiroclástica com clastos de quartzo e K-feldspato imersos numa matriz granolepidoblástica inequigranular constituída por biotita, quartzo e plagioclásio. Aumento total: 40x; (D) Rocha granoblástica a levemente lepidoblástica constituída por plagioclásio, quartzo, microclínio, e biotita. Aumento total: 40x. Abreviações segundo Whitney e Evans (2010).

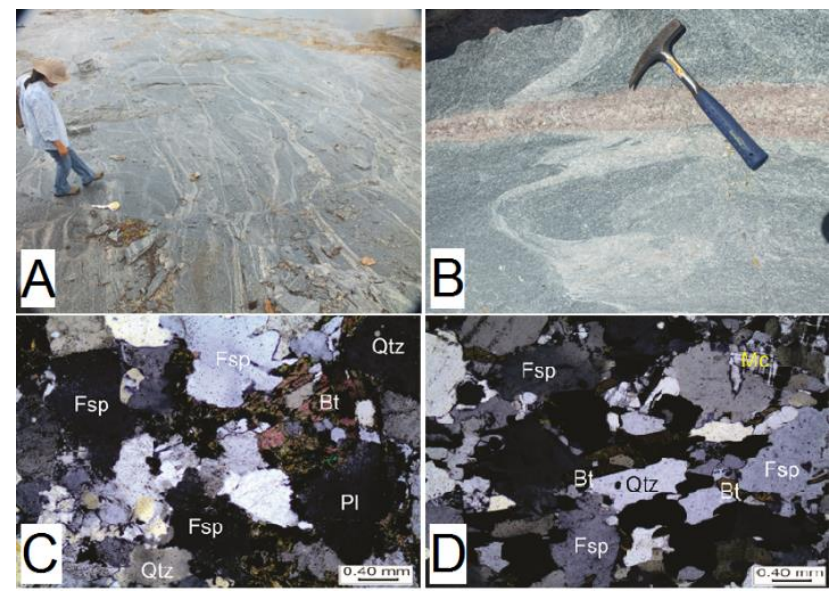

Figura 04 - Feições de campo e fotomicrografias do OMGO. (A) Feições migmatíticas nebulíticas características dessa unidade; (B) Evidências de bolsões leucossomáticos, mais jovens, que a encaixante, ricos em quartzo e $K$-feldspato; (C) Microestrutura granoblástica constituída por plagioclásio, K-feldspato, quartzo e biotita. Aumento total: 40x; (D) Idem ao anterior. Abreviações segundo Whitney e Evans (2010).

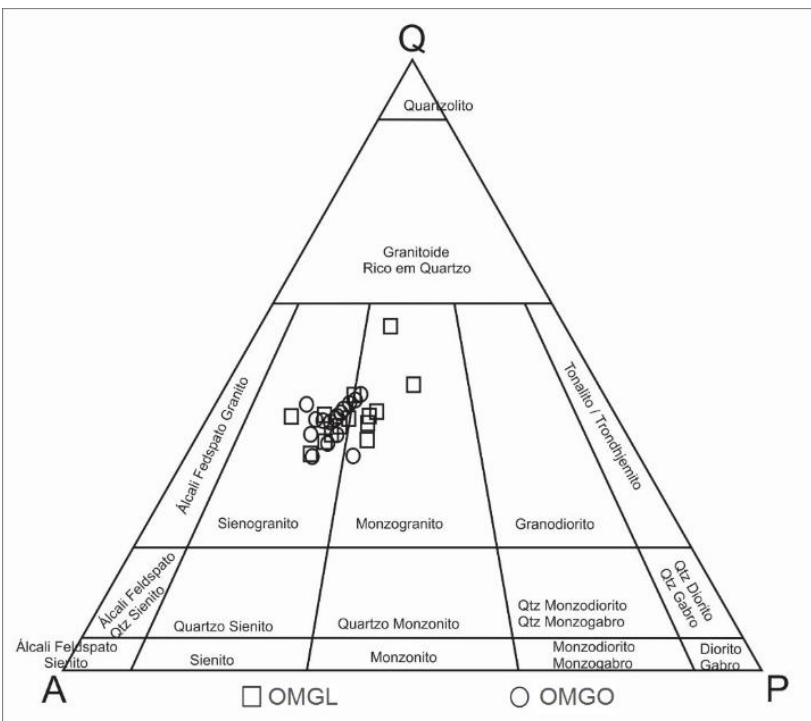

Figura 05 - Diagrama QAP (STRECKEISEN, 1976) para as amostras das duas unidades analisadas.

\subsection{Litoquímica}

A caracterização litoquímica dessa pesquisa leva em consideração os dados referentes aos elementos maiores, traço e terras raras, que permitiram elaborar diagramas de classificação, diagramas binários, ternários e multielementares, visando a interpretar o comportamento litoquímico de cada unidade e, alternativamente, quando possível, identificar a série ou séries magmáticas além do provável ambiente em que se formaram os protólitos dos migmatitos. A tabela contendo os dados litoquímicos pode ser visto nos apêndices 01 e 02.

\subsubsection{Elementos Maiores}

As rochas do domínio OMGL apresentam teor de $\mathrm{SiO}_{2}$ variando de $65,68 \%$ a $78,61 \%, \mathrm{Na}_{2} \mathrm{O}$ entre $2,59 \%$ e $4,99 \%, \mathrm{Al}_{2} \mathrm{O}_{3}$ de $11,11 \%$ a $18,42 \%$ e $\mathrm{CaO}$ variando de $2,9 \%$ a $1,18 \%$, sendo classificadas como peraluminosas, com $\mathrm{A} / \mathrm{CNK}$ variando de 1,38 a 2,21. Por sua vez as rochas do domínio OMGO apresentam teores de $\mathrm{SiO}_{2}$ variando de $67,8 \%$ a $74,57 \%, \mathrm{Na}_{2} \mathrm{O}$ entre $3,62 \%$ e $5,31 \%, \mathrm{Al}_{2} \mathrm{O}_{3}$ de $13,56 \%$ a $16,36 \%$ e $\mathrm{CaO}$ variando $1,26 \%$ a $2,81 \%$. Exibem razão A/CNK variando de 1,40 a 1,60, podendo ser classificadas como peraluminosas.

A partir dos diagramas para os elementos maiores (Figura 06), observa-se padrões díspares para as rochas das unidades OMGL e OMGO, com correlações negativas para $\mathrm{TiO}_{2}, \mathrm{P}_{2} \mathrm{O}_{5}$, $\mathrm{Al}_{2} \mathrm{O}_{3}, \mathrm{Na}_{2} \mathrm{O}$ e $\mathrm{CaO}$. Esse comportamento do $\mathrm{Al}_{2} \mathrm{O}_{3}$ e do $\mathrm{CaO}$ pode estar relacionado com a cristalização do protólito antes da migmatização. Com isso deve ter ficado registrado a possível cristalização simultânea de fenocristais de K-feldspato e plagioclásio, indicando o possível fracionamento desse último. $\mathrm{O}$ comportamento do $\mathrm{TiO}_{2}$ pode estar relacionado com fracionamento da titanita, bem como o $\mathrm{P}_{2} \mathrm{O}_{5}$ com apatita. Para o $\mathrm{K}_{2} \mathrm{O}$, observa-se que na unidade $\mathrm{OMGO}$, há correlação positiva, evidenciando o caráter potássico dessas rochas, corroborando com o caráter sienogranítico explicitado na figura 05. Observa- 
se, ainda, que há uma maior dispersão dos pontos representativos das amostras desses migmatitos que considera-se resultado da migmatização. Com efeito, verifica-se que as amostras da unidade OMGO sofreram migmatização mais importante que a unidade OMGL visto que nessa última os pontos ainda se mantêm com uma certa organização refletindo mais as características do protólito.
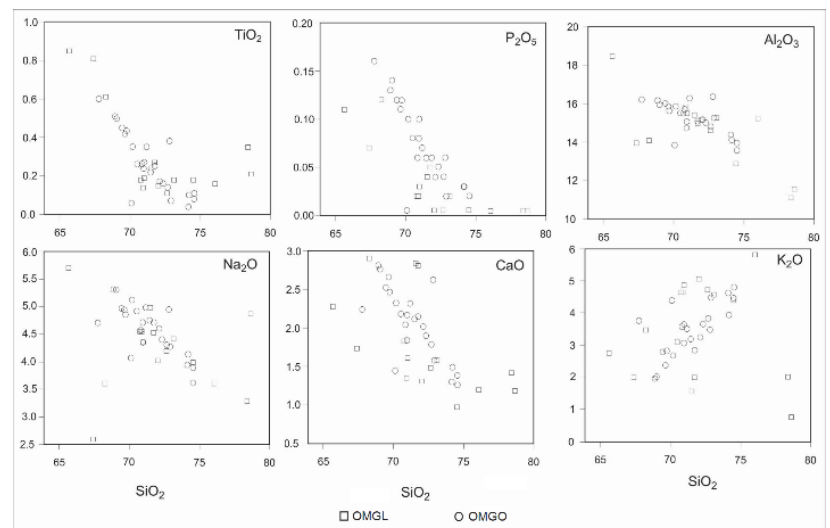

Figura 06 - Diagramas de variação química para os elementos maiores para as duas unidades estudadas.

Analisando o diagrama de Peccerillo e Taylor (1976) (Figura 07), observa-se, para as rochas OMGL, a existência de duas séries: a primeira cálcio-alcalina e a segunda cálcio-alcalina de alto $\mathrm{K}$, o que pode sugerir uma série evolutiva entre baixo e alto $\mathrm{K}$, ou seja, amostras mais enriquecidas e menos enriquecidas nesse elemento. Além disso, apesar da dispersão das amostras, pode-se inferir a ocorrência incipiente de cristalização fracionada dos protolitos desses migmatitos. As rochas OMGO, semelhantemente às anteriores, apresentam dois padrões bem definidos: o primeiro ocupando o campo da série cálcio-alcalina e o segundo, o campo da série cálcio-alcalina de alto K, com uma evolução linear de enriquecimento de $\mathrm{K}_{2} \mathrm{O}$.

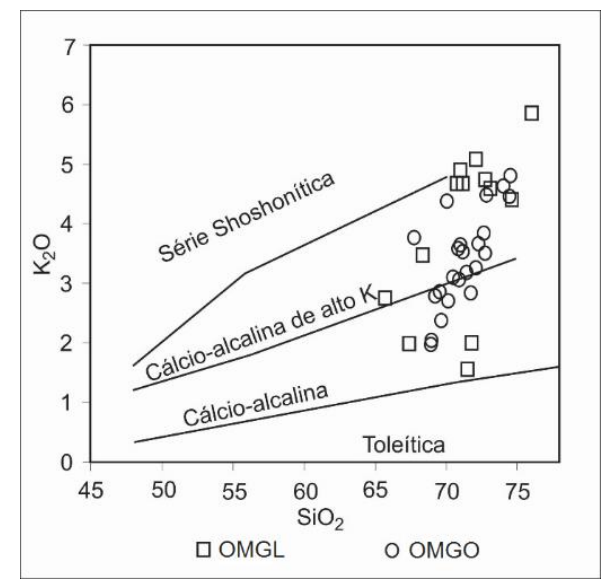

Figura 07 - Diagrama $\mathrm{SiO}_{2}$ versus $\mathrm{K}_{2} \mathrm{O}$ proposto por Peccerillo e Taylor (1976) para as duas unidades estudadas,
De acordo com o diagrama ternário de O'Connor (1965) (Figura 08A), as rochas OMGL ocupam os campos dos granitos com tendências para os granodioritos, enquanto as rochas OMGO se alojam no campo dos granitos, embora apresentem indícios de que as rochas menos evoluídas podem ter ligação com trondhjemitos.

A partir do diagrama Na-K-Ca de Barker e Arth (1976) (Figura 08B), com a inserção do campo composicional dos TTG's arqueanos de Martin (1994), observa-se que as rochas das duas unidades, OMGL e OMGO acompanham o trend cálcio-alcalino normal, mostrando uma nítida afinidade com a série homônima. Mais uma vez, verifica-se que os trends dos protólitos das duas unidades se iniciam próximo ao trend trondhjemítico.
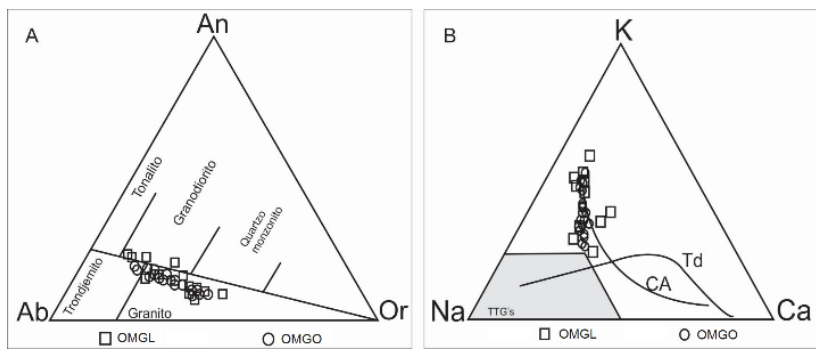

Figura $08-A-$ Diagrama ternário Ab-An-Or, proposto por O'Connor (1965). B - Diagrama Na-K-Ca (BARKER e ARTH, 1976), com campo na cor cinza referente aos TTG's arqueanos de Martin (1994), CA: Trend cálcio-alcalino. Td: trend trondjhemítico.

\subsubsection{Elementos Traço e Terras Raras}

As análises dos elementos traço das rochas da unidade OMGL mostram enriquecimento em LILE (Large Ion Litophile Elements) e empobrecimento em HFSE (High Field Strenght Elements), além de anomalias negativas em $\mathrm{Ta}, \mathrm{Nb}$ e $\mathrm{P}$ e positivas de $\mathrm{U}$ e Nd. As correlações negativas sugerem a diferenciação durante a cristalização do protólito. Com efeito, apesar da alta taxa de fusão parcial dessas rochas, restaram características do protólito após a fusão (Figura 09A). As rochas da unidade OMGO apresentam características de natureza cálcio-alcalina de alto $\mathrm{K}$, com enriquecimento em LILE e empobrecimento em HFSE, além das fortes anomalias negativas de $\mathrm{Nb}, \mathrm{Ta}, \mathrm{Sr}, \mathrm{Pe} \mathrm{Ti}$, sendo que os dois primeiros elementos sugerem um reflexo da fonte crustal do magma parental (Figura 09B). A variação dos teores de $\mathrm{Sr}$ pode sugerir o fracionamento do plagioclásio. Por outro lado, as anomalias positivas de Th e Rb podem sugerir um envolvimento de crosta continental durante a gênese dessas rochas.

Observando os elementos Terras Raras, as rochas da unidade OMGL apresentam enriquecimento em ETRL (Elementos Terras Raras Leves) e empobrecimento em ETRP (Elementos Terras Raras Pesados), além de anomalia negativa de Eu, evidenciando a acumulação de plagioclásio (Figura 09C). Com relação à unidade OMGO, observa-se forte fracionamento, sem anomalias significativas de $\mathrm{Eu}$, ora negativa, indicando fracionamento do feldspato durante o processo de fusão, e ora positiva, refletindo o acúmulo de feldspato durante a cristalização (Figura 09D). O comportamento desarmônico dos ETRL, sugere a importância do metassomatismo na formação desses migmatitos. 


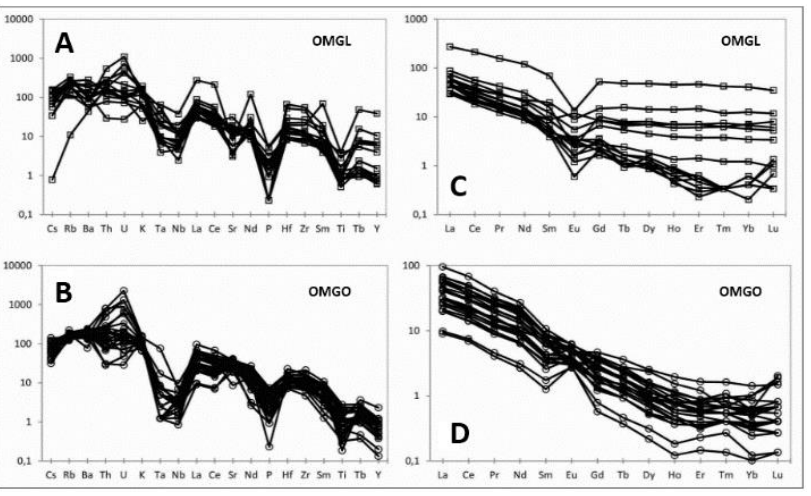

Figura $09-A$ e B - Diagramas multielementares normalizados para o manto primitivo de Sun e McDonough (1989) das unidades OMGL (A) e OMGO (B). C e D-Diagramas dos elementos Terras Raras normalizados para o manto primitivo de Sun e McDonough (1989) das unidades OMGL (C) e OMGO (D).

\subsubsection{Ambiência Tectônica}

A partir do diagrama binário de Pearce et al. (1984) (Figura 10), observa-se que, para as rochas da unidade OMGL, os pontos representativos das análises químicas da maioria ocupam a transição entre os ambientes sin-colisionais e de arco vulcânico, situando-se mais nesse último campo. O deslocamento de algumas amostras para o campo sin-colisional pode ser devido às modificações químicas dessas rochas durante a migmatização, em função do enriquecimento do elemento químico $\mathrm{Rb}$ e da presença substancial de minerais como o feldspato e a biotita. No que diz respeito às rochas da unidade OMGO, elas ocupam basicamente o campo de rochas de ambiente de arco vulcânico.

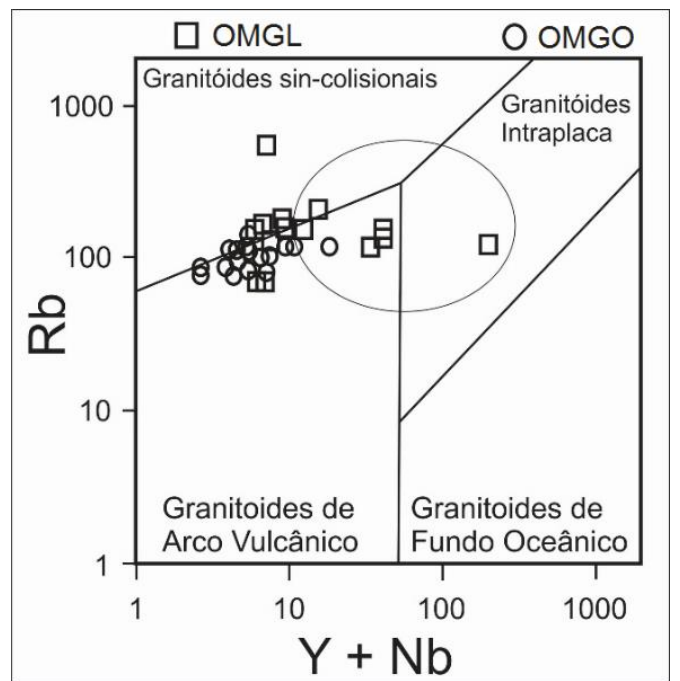

Figura 10 - Diagrama geotectônico de Pearce et al., (1984).

\section{CONSIDERAÇÕES FINAIS}

Os resultados obtidos a partir dessa pesquisa vêm contribuindo para o conhecimento geológico da porção norte do Cinturão Salvador-Esplanada-Boquim (CSEB), trazendo à tona novas informações e dados relevantes sobre a origem e evolução geológica da região, algumas delas interpretadas nesse artigo e outras concluídas e inseridas em Barbosa et al. (2018).

Em campo, constatou-se que as rochas da área de estudo mostram um maior grau de migmatização na sua porção oeste, na unidade $\mathrm{OMGO}$, diminuindo o grau desses processos à medida que se caminha para leste, unidade OMGL.

Petrograficamente observou-se similaridades na composição das duas unidades, com pequenas variações nas quantidades de biotita, o tipo de plagioclásio existente e a ocorrência de minerais acessórios. A relação envolvendo os raros clinopiroxênios, a hornblenda e a biotita castanha/vermelha, deve ser um indicativo de abaixamento das condições de metamorfismo na região, corroborada pela presença pontual da hornblenda verdeacastanhada e da biotita marrom. Esses minerais são comuns em áreas de intenso processo deformacional, além da ocorrência, nessas áreas, de outros filossilicatos (muscovita, clorita). Reiterase a manutenção da divisão, seguindo o trabalho de Barbosa et al. (2018).

Litoquimicamente a unidade OMGO apresentou rochas variando de cálcio-alcalina a cálcio-alcalina de alto $\mathrm{K}$, classificadas como sendo graníticas, oriundas de um ambiente de arco de ilha, ainda com pequena influência pós-colisional. De acordo com a análise dos elementos maiores, traço e terras raras, concluiu-se que as rochas dessa unidade sofreram cristalização precoce de fenocristais de feldspato potássico e plagioclásio, sendo estes restaram preservados durante a fusão parcial dessas rochas. Também esses minerais sugerem o envolvimento da crosta continental durante a formação dos protólitos.

As rochas da unidade OMGL variam de cálcio-alcalina a cálcio-alcalina de alto $\mathrm{K}$, associadas a um ambiente de arco vulcânico a sin-colisional. A análise dos seus elementos maiores, traço e Terras raras sugerem a possibilidade de mistura de magmas de fontes distintas, bem como contaminação crustal.

Essas rochas, portanto, seriam provenientes de um ambiente de arco de ilhas e, durante a sua formação, ocorreram processos de diferenciação e contaminação crustal. A partir daí, elas foram submetidas a intenso processo de migmatização durante os processos metamórficos e retrometamórficos, que moldaram suas características físico-químicas, bem como as assinaturas litoquímicas.

\section{REFERÊNCIAS}

Alkmim F.F.; Brito Neves B.D.; Alves J.C.. Arcabouço tectônico do Cráton do São Francisco-uma revisão. In Dominguez, J.M.L.; Misi, A. (ed.) O Cráton do São Francisco. SBGNúcleo BA/SE, 1993. 1, 45-62.

Barbosa, J.S.F.. The granulites of the Jequié complex and Atlantic mobile belt, southern Bahia, Brazil - An expression of ArcheanProterozoic plate convergence. In: Vielzeuf D. \& Vidal P. (ed.). Granulites and crustal evolution. Clordrecht, Kluwer Académie, 1990. p. 195-221. 
Barbosa, J.S.F.; Pinto, M.S.; Cruz, S.P.; Souza, J.S.. Terrenos Metamórficos do Embasamento, In Barbosa, J. S. F. (ed.) Geologia da Bahia: pesquisa e atualização. Série Publicações Especiais, 13 Convênio CBPM/UFBAIGEO/SBG, 2012. $2 \mathrm{v}$.

Barbosa, J.S.F.; Marinho, M.M.; Menezes Leal, A.B.; Oliveira, E.M.; Souza-Oliveira, J.S.; Argollo, R.M.; Lana, C.; Barbosa, R.G.; Santos, L.T.L.. As raízes granulíticas do cinturão Salvador-Esplanada-Boquim, Cráton do São Francisco, Bahia-Sergipe, Brasil. Geologia USP. Série Científica, 2018, 18(2), 103-128.

Barker, F.; Arth, J.G.. Generation of trondhjemitic-tonalitic liquids and Archaean bimodal trondhjemite-basalt suites. Geology, 1976. 4: 596-600.

D'el-Rey Silva, L.J.H.. New Sm-Nd data of (meta)sediments accross the São Francisco Craton-Sergipano Belt boundary, and from the Arauá dykes: Implications on Provenance Studies. In III Simpósio sobre o Cráton do São Francisco, Salvador, 14 a 18 de agosto de 2005, Anais III SCSF, 2005. p. $155-158$.

GEOTERM-NE.. Geração de calor nas bacias de Cumuruxatiba, Jequitinhonha, Sergipe-Alagoas e Pernambuco-Paraíba, e nos embasamentos a elas adjacentes. Patrocinado pelo Promob-Cenpes-Petrobras e executado pelo CPGG-UFBA, 2010.

Hasui, Y.. Cráton São Francisco, In Almeida, F.F.M.; Bartorelli, A.; Carneiro, F.D.R.; Hasui, Y.; (eds.) Geologia do Brasil. Ed. Beca, São Paulo, 2013. 900p.

Martin, H.. The Archean grey gneisses and the genesis of the continental crust. In Condie, K.C. (ed.), The Archean Crustal Evolution, Developments in Precambrian Geology. Elsevier, Amsterdam, 1994. p. 205-259.

O'Connor, J.T.. A classification for quartz rich igneous rock based on feldspar rations. USGS. Prof. Pap., 1965. 525B: 79-84.

Oliveira, E.M.. Petrografia, litogeoquímica e geocronologia das rochas granulíticas da parte norte do Cinturão SalvadorEsplanada-Boquim, Bahia-Sergipe. Tese de Doutorado, Programa de Pós Graduação em Geologia, Instituto de Geociências, Universidade Federal da Bahia, 2014. 220p.

Oliveira Jr., T.R.. Geologia do extremo nordeste do Cráton São Francisco, Bahia. Dissertação de Mestrado, Programa de Pós Graduação em Geologia, Instituto de Geociências, Universidade Federal da Bahia, 1990. 126p.

Pearce, J.A.; Harris, N.B.W.; Tindle, A.G.. Trace element discrimination diagrams for the tectonic interpretation of granitic rocks. Journal of Petrology, 1984. 25: 956-983.

Peccerillo, A.; Taylor, S.R.. Geochemistry of eocene calcalkaline volcanic rocks from the Kastamonu area, northern
Turkey. Contributions to Mineralogy and Petrology, 1976. 58: 63-81.

Santos, R.A.; Martins, A.A.M.; Neves, J.P.; Leal, R.A.. Programa Levantamentos Geológicos Básicos Do Brasil - PLGB. Geologia e Recursos Minerais Do Estado De Sergipe. Escala 1:250.000. Texto Explicativo Do Mapa Geológico Do Estado De Sergipe. Brasília: CPRM/DIEDIG/DEPAT; CODISE, 2001. 156p.

Silva, L.C.; Armstrong, R.; Delgado, I.M.; Pimentel, M.M.; Arcanjo, J.B.; Melo, R.C.; Teixeira, L.R.; Jost, H.; Pereira, L.H.M.; Cardoso Filho, J.M.. Reavaliação da evolução geológica em terrenos pré-cambrianos brasileiros, com base em novos dados U-Pb SHRIMP, Parte I: Limite centrooriental do Cráton São Francisco na Bahia. Revista Brasileira de Geociências, 2002. 32(4): 501-512.

Streckeisen, A.. To each plutonic rock it's proper name. Earth Science Review, 1976. 12: 1-33.

Sun, S.S.; McDonough, W.F.. Chemical and isotopic systematic of oceanic basalts for mantle composition and process. In SAUNDER, A.D.; NORRY, M.J.; (ed.) Magmatism in the ocean basins. Geological Society, Special Publication, 1989. 42: 313-345.

Whitney, D.L.; Evans, B.W.. Abbreviations for names of rockforming minerals. American Mineralogist, 2010. 95:185187.

Recebido em: 04/12/2019

Aceito para publicação em: 18/08/2020 


\begin{tabular}{|c|c|c|c|c|c|c|c|c|c|c|c|c|c|c|c|}
\hline Amostra & MV-10 & MV-11 & MV-12 & MV-13 & MV-16B & MV-17 & GeSe 011 & GeSe 012-A & GeSe 056 & GeSe 059 & GeSe 062 & GeSe 077 & GeSe 078-B & GeSe 092 & GeSe 118 \\
\hline $\mathrm{SiO}_{2}$ & 73,14 & 67,43 & 65,68 & 78,61 & 76,05 & 78,39 & 72,67 & 71,01 & 71,76 & 74,51 & 71,55 & 72,04 & 68,3 & 70,77 & 70,93 \\
\hline $\mathrm{TiO}_{2}$ & 0,18 & 0,81 & 0,85 & 0,21 & 0,16 & 0,35 & 0,11 & 0,19 & 0,27 & 0,18 & 0,24 & 0,15 & 0,61 & 0,18 & 0,14 \\
\hline $\mathrm{Al}_{2} \mathrm{O}_{3}$ & 15,25 & 13,93 & 18,42 & 11,55 & 15,23 & 11,11 & 14,6 & 15,5 & 14,96 & 12,87 & 15,39 & 15,17 & 14,08 & 15,47 & 15,82 \\
\hline $\mathrm{Fe}_{2} \mathrm{O}_{\mathrm{T}}$ & 2,76 & 13,95 & 7,25 & 4,43 & 1,01 & 5,65 & 1,79 & 1,78 & 2,61 & 2,79 & 2,52 & 1,68 & 5,66 & 1,93 & 1,84 \\
\hline $\mathrm{MnO}$ & 0,005 & 0,06 & 0,01 & 0,005 & 0,005 & 0,005 & 0,03 & 0,02 & 0,04 & 0,05 & 0,03 & 0,03 & 0,11 & 0,03 & 0,03 \\
\hline $\mathrm{MgO}$ & 0,28 & 2,99 & 2,71 & 0,09 & 0,2 & 1,14 & 0,26 & 0,25 & 0,64 & 0,06 & 0,56 & 0,2 & 0,63 & 0,66 & 0,17 \\
\hline $\mathrm{CaO}$ & 1,57 & 1,73 & 2,27 & 1,18 & 1,2 & 1,42 & 1,48 & 1,61 & 2,81 & 0,97 & 2,84 & 1,31 & 2,9 & 1,83 & 1,35 \\
\hline $\mathrm{Na}_{2} \mathrm{O}$ & 4,41 & 2,59 & 5,7 & 4,87 & 3,61 & 3,28 & 4,2 & 4,35 & 4,53 & 4 & 4,99 & 4,01 & 3,61 & 4,55 & 4,55 \\
\hline $\mathrm{K}_{2} \mathrm{O}$ & 4,55 & 1,99 & 2,75 & 0,75 & 5,81 & 2 & 4,71 & 4,86 & 1,99 & 4,39 & 1,55 & 5,05 & 3,47 & 4,65 & 4,65 \\
\hline $\mathrm{P}_{2} \mathrm{O}_{5}$ & 0,02 & 0,07 & 0,11 & 0,005 & 0,005 & 0,005 & 0,005 & 0,03 & 0,05 & 0,005 & 0,04 & 0,005 & 0,12 & 0,02 & 0,02 \\
\hline $\mathrm{Cr}_{2} \mathrm{O}_{3}$ & 0,005 & 0,03 & 0,02 & 0,01 & 0,005 & 0,005 & 0,001 & - & 0,001 & 0,001 & 0,001 & - & - & - & 0,001 \\
\hline LOI & 0,39 & 0,97 & 0,6 & 0,41 & 0,35 & 0,78 & 0,14 & 0,38 & 0,33 & 0,19 & 0,27 & 0,37 & 0,29 & 0,49 & 0,49 \\
\hline Total & 101,26 & 103,12 & 103,32 & 101,28 & 103,41 & 102,63 & 102,13 & 102,41 & 99,05 & 100,54 & 100,54 & 100,13 & 99,89 & 99,96 & 98,37 \\
\hline $\mathrm{A} / \mathrm{CNK}$ & 1,45 & 2,21 & 1,72 & 1,70 & 1,43 & 1,66 & 1,41 & 1,43 & 1,60 & 1,38 & 1,64 & 1,46 & 1,41 & 1,40 & 1,50 \\
\hline Cs & 2,65 & 1,09 & 4,46 & 0,025 & 2,15 & 3,84 & 3,69 & 3,36 & 2,21 & 1,09 & 4,51 & 1,82 & 4,82 & 3,33 & 5,04 \\
\hline $\mathrm{Rb}$ & 154,4 & 104,2 & 122,1 & 6,9 & 165,9 & 119,3 & 180,9 & 127 & 69,8 & 145,8 & 73,5 & 161 & \begin{tabular}{|l|}
141 \\
\end{tabular} & 157,1 & 211 \\
\hline $\mathrm{Ba}$ & 1245 & 857 & 540 & 304 & 1959 & 386 & 646 & 1529 & 641 & 1280 & 384 & 1314 & 936 & 1302 & 683 \\
\hline $\mathrm{Th}$ & 23,8 & 2,5 & 46,1 & 15,3 & 11,9 & 13,4 & 15,4 & 13,6 & 13,1 & 19,3 & 6,7 & 20,5 & 10,6 & 8,9 & 23 \\
\hline $\mathrm{U}$ & 4,51 & 0,58 & 23,22 & 1,92 & 1,81 & 2,88 & 8,83 & 3,06 & 1,83 & 2,45 & 1,52 & 15,31 & 2,2 & 1,9 & 9,75 \\
\hline $\mathrm{Nb}$ & 7,37 & 4,57 & 26,82 & 8,83 & 1,75 & 8,14 & 5,85 & 3,93 & 3,56 & 9,6 & 3,27 & 5,27 & 13,95 & 3,29 & 8,6 \\
\hline $\mathrm{Ta}$ & 2,21 & 0,41 & 2,67 & 1,85 & 0,36 & 0,76 & 0,38 & 0,32 & 0,34 & 0,85 & 0,26 & 0,38 & 1 & 0,16 & 1,37 \\
\hline $\mathrm{La}$ & 50,9 & 20,4 & 187,6 & 30,5 & 32,6 & 21 & 20,2 & 38,7 & 23,5 & 60,3 & 30,6 & 41,9 & 41,6 & 31,4 & 31 \\
\hline $\mathrm{Ce}$ & 85,3 & 40,2 & 376,2 & 64,4 & 51,2 & 36,1 & 32,1 & 57,4 & 36 & 100,8 & 38 & 60,8 & 69,5 & 41,8 & 47,5 \\
\hline $\mathrm{Pr}$ & 8,47 & 4,5 & 43,14 & 7,83 & 5,19 & 4,05 & 3,34 & 6,06 & 3,9 & 11,63 & 4,25 & 6,18 & 7,95 & 3,95 & 4,77 \\
\hline $\mathrm{Sr}$ & 262 & 118 & 165 & 71 & 339 & 85 & 279,8 & 380 & 292,4 & 64,5 & 413,2 & 257,5 & 226,1 & \begin{tabular}{|l|}
658,3 \\
\end{tabular} & 216 \\
\hline $\mathrm{Nd}$ & 27,4 & 15,8 & 162 & 30,2 & 16,9 & 16,9 & 11,5 & 20 & 13,8 & \begin{tabular}{|l|}
41,9 \\
\end{tabular} & 14,1 & \begin{tabular}{|l|}
20,5 \\
\end{tabular} & \begin{tabular}{|l}
29,8 \\
\end{tabular} & \begin{tabular}{|l|}
13,2 \\
\end{tabular} & \begin{tabular}{|l|}
16,7 \\
\end{tabular} \\
\hline $\mathrm{Sm}$ & 3,9 & 3,8 & 30,7 & 8,7 & 2,1 & 3,9 & 2,1 & 2,4 & 2,1 & 7 & 1,7 & 2,9 & 5,4 & 2 & 2,5 \\
\hline $\mathrm{Zr}$ & 140 & 88,1 & 218 & 619 & 116 & 531 & 75,6 & \begin{tabular}{|l|}
154,9 \\
\end{tabular} & \begin{tabular}{|l|}
142,2 \\
\end{tabular} & 304 & 117,2 & 121 & \begin{tabular}{|l|}
256,3 \\
\end{tabular} & \begin{tabular}{|l|}
95,1 \\
\end{tabular} & \begin{tabular}{|l|}
141,6 \\
\end{tabular} \\
\hline $\mathrm{Hf}$ & 5,36 & 2,5 & 6,01 & 20,59 & 3,62 & 16,19 & 2,63 & 4,91 & 4,18 & 9,14 & 4,27 & 4 & 6,86 & 2,93 & 5,5 \\
\hline $\mathrm{Eu}$ & 0,57 & 0,58 & 2,25 & 1,49 & 0,2 & 1,98 & 0,28 & 0,48 & 0,6 & 0,39 & 0,57 & 0,26 & 0,92 & 0,1 & 0,4 \\
\hline $\mathrm{Gd}$ & 2,05 & 3,95 & 31,11 & 8,81 & 0,97 & 4,99 & 1,4 & 1,25 & 1,67 & 6,1 & 1,16 & 2,14 & 5,09 & 1,28 & 1,63 \\
\hline $\mathrm{Tb}$ & 0,1 & 0,58 & 5,21 & 1,68 & 0,12 & 0,71 & 0,15 & 0,1 & 0,18 & 0,85 & 0,12 & 0,18 & \begin{tabular}{|l|}
0,79 \\
\end{tabular} & 0,12 & 0,26 \\
\hline Dy & 1,08 & 3,31 & 35,22 & 10,5 & 0,64 & 5,16 & 0,7 & 0,77 & 0,94 & 5,92 & 0,63 & \begin{tabular}{|l|}
1,09 \\
\end{tabular} & 5,13 & 0,83 & 1,34 \\
\hline $\mathrm{Y}$ & 5 & 18 & 175 & 48 & 5 & 27 & 3,27 & 3,74 & 3,35 & 31,56 & 2,92 & 4,38 & 27,63 & 2,77 & 6,91 \\
\hline Ho & 0,07 & 0,64 & 7,44 & 2,3 & 0,15 & 1,16 & 0,08 & 0,1 & 0,12 & 1,13 & 0,08 & 0,14 & 0,98 & 0,1 & 0,22 \\
\hline $\mathrm{Er}$ & 0,14 & 1,8 & 22,41 & 7,03 & 0,26 & 3,37 & 0,11 & 0,3 & 0,3 & 3,38 & 0,26 & 0,22 & 2,91 & 0,17 & 0,68 \\
\hline $\mathrm{Tm}$ & 0,025 & 0,28 & 3,12 & 0,88 & 0,025 & 0,46 & 0,025 & 0,025 & 0,025 & 0,55 & 0,025 & 0,025 & 0,46 & 0,025 & 0,09 \\
\hline $\mathrm{Yb}$ & 0,1 & 1,7 & 20,1 & 6,2 & 0,2 & 3,5 & 0,2 & 0,3 & 0,2 & 3,3 & 0,2 & 0,2 & 2,8 & 0,2 & 0,6 \\
\hline $\mathrm{Lu}$ & 0,05 & 0,25 & 2,58 & 0,87 & 0,08 & 0,59 & 0,025 & 0,025 & 0,025 & 0,45 & 0,08 & 0,1 & 0,39 & 0,025 & 0,07 \\
\hline
\end{tabular}

Apêndice 01: Análises químicas em rocha total de elementos maiores (\% em peso), traço (ppm) e terras raras (ppm) da unidade OMGL. 


\begin{tabular}{|c|c|c|c|c|c|c|c|c|c|c|c|c|}
\hline Amostra & MV-02 & MV-04 & MV-08 & GeSe 014 & GeSe 032A & GeSe 032A1 & GeSe 032B & GeSe 032B1 & GeSe 033A & GeSe 033A1 & GeSe 033C & GeSe 034A \\
\hline $\mathrm{SiO}_{2}$ & 71,18 & 72,82 & 70,15 & 70,98 & 70,23 & 70,85 & 72,35 & 67,8 & 68,96 & 69,06 & 74,57 & 74,56 \\
\hline $\mathrm{TiO}_{2}$ & 0,35 & 0,38 & 0,06 & 0,27 & 0,35 & 0,26 & 0,16 & 0,6 & 0,51 & 0,5 & 0,08 & 0,11 \\
\hline $\mathrm{Al}_{2} \mathrm{O}_{3}$ & 16,26 & 16,36 & 13,83 & 15,06 & 15,84 & 15,7 & 15 & 16,2 & 16,14 & 15,94 & 13,96 & 13,56 \\
\hline $\mathrm{Fe}_{2} \mathrm{O} 3_{\mathrm{T}}$ & 3,77 & 3,80 & 1,64 & 2,25 & 2,17 & 1,79 & 1,4 & 2,99 & 2,68 & 2,9 & 0,99 & 1,39 \\
\hline $\mathrm{MnO}$ & 0,005 & 0,005 & 0,005 & 0,04 & 0,02 & 0,02 & 0,02 & 0,03 & 0,02 & 0,03 & 0,01 & 0,02 \\
\hline $\mathrm{MgO}$ & 0,68 & 0,59 & 0,16 & 0,76 & 0,54 & 0,48 & 0,31 & 0,84 & 0,81 & 0,81 & 0,11 & 0,16 \\
\hline $\mathrm{CaO}$ & 2,31 & 2,62 & 1,44 & 2,16 & 2,32 & 2,04 & 1,89 & 2,24 & 2,81 & 2,76 & 1,38 & 1,26 \\
\hline $\mathrm{Na}_{2} \mathrm{O}$ & 4,98 & 4,95 & 4,07 & 4,71 & 5,12 & 4,59 & 4,41 & 4,71 & 5,31 & 5,31 & 3,89 & 3,62 \\
\hline $\mathrm{K}_{2} \mathrm{O}$ & 3,51 & 3,48 & 4,38 & 3,05 & 2,68 & 3,57 & 3,64 & 3,75 & 1,95 & 2,02 & 4,45 & 4,79 \\
\hline $\mathrm{P}_{2} \mathrm{O}_{5}$ & 0,07 & 0,06 & 0,005 & 0,1 & 0,1 & 0,06 & 0,05 & 0,16 & 0,13 & 0,14 & 0,02 & 0,02 \\
\hline $\mathrm{Cr}_{2} \mathrm{O}_{3}$ & 0,005 & 0,01 & 0,005 & 0,001 & 0,001 & 0,001 & 0,001 & 0,001 & 0,001 & 0,001 & 0,001 & 0,001 \\
\hline LOI & 0,25 & 0,24 & 0,18 & 0,4 & 0,4 & 0,4 & 0,05 & 0,4 & 0,4 & 0,3 & 0,3 & 0,3 \\
\hline Total & 101,74 & 102,95 & 95,33 & 99,76 & 99,77 & 99,76 & 99,74 & 99,7 & 99,73 & 99,77 & 99,75 & 99,81 \\
\hline $\mathrm{A} / \mathrm{CNK}$ & 1,51 & 1,48 & 1,40 & 1,52 & 1,57 & 1,54 & 1,51 & 1,51 & 1,60 & 1,58 & 1,44 & 1,40 \\
\hline Cs & 3,89 & 3,45 & 1,33 & 3,7 & 3,6 & 3,1 & 1,9 & 3,7 & 4,5 & 3,9 & 1,5 & 2 \\
\hline $\mathrm{Rb}$ & 105,8 & 102,3 & 119 & 116,8 & 82,3 & 95,9 & 87,4 & 117,4 & 92,8 & 95,2 & 113,5 & 141,1 \\
\hline $\mathrm{Ba}$ & 1406 & 1048 & 902 & 1262 & 1016 & 1416 & 1575 & 1397 & 964 & 941 & 1669 & 1088 \\
\hline Th & 21,9 & 21,2 & 41,4 & 16,4 & 9,9 & 8,9 & 6,1 & 21,6 & 16,8 & 16,9 & 68 & 66,4 \\
\hline $\mathrm{U}$ & 7,02 & 13,61 & 27,66 & 3,7 & 4,3 & 3,2 & 3,3 & 2,5 & 2,9 & 3,3 & 18,6 & 47,7 \\
\hline $\mathrm{Nb}$ & 2,18 & 2,17 & 4,98 & 7 & 2,6 & 2,2 & 1,8 & 3,9 & 2,8 & 2,6 & 1 & 1,7 \\
\hline $\mathrm{Ta}$ & 0,36 & 0,33 & 3,1 & 0,7 & 0,3 & 0,2 & 0,2 & 0,3 & 0,2 & 0,2 & 0,1 & 0,2 \\
\hline $\mathrm{La}$ & 42,3 & 21,2 & 21,2 & 40,8 & 29,5 & 22,2 & 13,6 & 65,5 & 45,9 & 45,9 & 18,4 & 28,9 \\
\hline $\mathrm{Ce}$ & 74,9 & 35,8 & 39,2 & 64,6 & 54,5 & 42,4 & 24,9 & 120,3 & 85,9 & 89 & 35 & 54,7 \\
\hline $\operatorname{Pr}$ & 7,68 & 4,5 & 3,95 & 7,72 & 5,72 & 4,11 & 2,44 & 11,12 & 8,84 & 8,58 & 3,4 & 5,77 \\
\hline $\mathrm{Sr}$ & 674 & 639 & 391 & 664 & 668,4 & 698,7 & 623 & 785,4 & 870 & 821,8 & 525,5 & 404,7 \\
\hline $\mathrm{Nd}$ & 25,5 & 23,1 & 15,2 & 27,4 & 20,4 & 13,8 & 8,6 & 36,5 & 30,9 & 28,8 & 11,5 & 19,6 \\
\hline $\mathrm{Sm}$ & 3,9 & 3,2 & 3,1 & 3,9 & 2,79 & 1,92 & 1,14 & 4,72 & 3,95 & 3,65 & 1,65 & 2,8 \\
\hline $\mathrm{Zr}$ & 137 & 123 & 84 & 118,7 & 149,8 & 94,4 & 79,9 & 235,8 & 182,6 & 171,2 & 181,6 & 107 \\
\hline $\mathrm{Hf}$ & 3,91 & 4,74 & 4,17 & 3,3 & 4,2 & 2,5 & 2,7 & 5,5 & 4,9 & 4,9 & 7 & 3,9 \\
\hline $\mathrm{Eu}$ & 0,84 & 0,59 & 0,46 & 0,8 & 0,78 & 0,67 & 0,63 & 1,02 & 1,05 & 1,05 & 0,49 & 0,45 \\
\hline $\mathrm{Gd}$ & 2,18 & 1,56 & 2,43 & 2,77 & 1,63 & 1,05 & 0,72 & 2,32 & 2,05 & 2,05 & 1,07 & 1,53 \\
\hline $\mathrm{Tb}$ & 0,27 & 0,21 & 0,3 & 0,39 & 0,2 & 0,12 & 0,1 & 0,3 & 0,25 & 0,25 & 0,16 & 0,19 \\
\hline Dy & 1,15 & 0,68 & 1,74 & 1,86 & 0,87 & 0,5 & 0,4 & 1,19 & 0,98 & 0,98 & 0,68 & 0,85 \\
\hline $\mathrm{Y}$ & 5 & 5 & 5 & 10,5 & 4,2 & 2,3 & 2 & 5,5 & 4 & 4 & 3,5 & 3,5 \\
\hline Ho & 0,18 & 0,17 & 0,25 & 0,32 & 0,13 & 0,07 & 0,07 & 0,19 & 0,13 & 0,13 & 0,13 & 0,13 \\
\hline $\mathrm{Er}$ & 0,42 & 0,35 & 0,58 & 0,79 & 0,29 & 0,19 & 0,15 & 0,42 & 0,27 & 0,27 & 0,4 & 0,29 \\
\hline $\mathrm{Tm}$ & 0,08 & 0,07 & 0,05 & 0,12 & 0,04 & 0,03 & 0,03 & 0,07 & 0,04 & 0,04 & 0,06 & 0,05 \\
\hline $\mathrm{Yb}$ & 0,3 & 0,5 & 0,5 & 0,7 & 0,28 & 0,15 & 0,16 & 0,42 & 0,25 & 0,25 & 0,31 & 0,27 \\
\hline
\end{tabular}


\begin{tabular}{|l|l|l|l|l|l|l|l|l|l|l|l|}
$\mathrm{Lu}$ & 0,15 & 0,12 & 0,14 & 0,11 & 0,04 & 0,02 & 0,02 & 0,06 & 0,03 & 0,03 & 0,06 \\
\hline
\end{tabular} Apêndice 01: Análises químicas em rocha total de elementos maiores (\% em peso), traço (ppm) e terras raras (ppm) da unidade OMGO.

\begin{tabular}{|c|c|c|c|c|c|c|c|c|c|c|c|}
\hline Amostra & $\mathrm{GeSe} 034 \mathrm{~A} 1$ & GeSe 034B & GeSe $034 \mathrm{C}$ & GeSe 034E & GeSe 035 & GeSe $035 \mathrm{~A} 1$ & GeSe 036A & $\mathrm{GeSe} 036 \mathrm{~A} 1$ & GeSe 036B & GeSe 048 & GeSe 048A1 \\
\hline $\mathrm{SiO}_{2}$ & 69,46 & 69,77 & 72,93 & 74,16 & 71,77 & 71,46 & 72,15 & 72,69 & 69,7 & 70,99 & 70,54 \\
\hline $\mathrm{TiO}_{2}$ & 0,45 & 0,43 & 0,07 & 0,04 & 0,25 & 0,22 & 0,17 & 0,14 & 0,42 & 0,24 & 0,26 \\
\hline $\mathrm{Al}_{2} \mathrm{O}_{3}$ & 15,98 & 15,61 & 15,25 & 14,38 & 15,08 & 15,42 & 15,14 & 14,78 & 15,85 & 14,72 & 15,52 \\
\hline $\mathrm{Fe}_{2} \mathrm{O}_{\mathrm{T}}$ & 2,53 & 2,75 & 0,74 & 1,04 & 2,07 & 1,81 & 1,56 & 1,39 & 2,58 & 1,97 & 2,02 \\
\hline $\mathrm{MnO}$ & 0,04 & 0,03 & 0,005 & 0,005 & 0,02 & 0,02 & 0,02 & 0,01 & 0,02 & 0,02 & 0,02 \\
\hline $\mathrm{MgO}$ & 0,71 & 0,69 & 0,14 & 0,09 & 0,52 & 0,48 & 0,32 & 0,27 & 0,82 & 0,7 & 0,73 \\
\hline $\mathrm{CaO}$ & 2,52 & 2,46 & 1,58 & 1,3 & 2,15 & 2,11 & 2,01 & 1,78 & 2,66 & 1,84 & 2,18 \\
\hline $\mathrm{Na}_{2} \mathrm{O}$ & 4,97 & 4,86 & 4,28 & 3,94 & 4,71 & 4,75 & 4,61 & 4,31 & 4,95 & 4,35 & 4,92 \\
\hline $\mathrm{K}_{2} \mathrm{O}$ & 2,79 & 2,82 & 4,47 & 4,62 & 2,83 & 3,17 & 3,23 & 3,82 & 2,36 & 3,64 & 3,09 \\
\hline $\mathrm{P}_{2} \mathrm{O}_{5}$ & 0,12 & 0,12 & 0,02 & 0,03 & 0,06 & 0,06 & 0,04 & 0,04 & 0,11 & 0,08 & 0,08 \\
\hline $\mathrm{Cr}_{2} \mathrm{O}_{3}$ & 0,001 & 0,001 & 0,001 & 0,001 & 0,001 & 0,001 & 0,001 & 0,001 & 0,001 & 0,003 & 0,002 \\
\hline LOI & 0,2 & 0,2 & 0,3 & 0,3 & 0,3 & 0,3 & 0,5 & 0,6 & 0,3 & 1,1 & 0,4 \\
\hline Total & 99,76 & 99,74 & 99,78 & 99,91 & 99,77 & 99,8 & 99,78 & 99,86 & 99,76 & 99,71 & 99,77 \\
\hline $\mathrm{A} / \mathrm{CNK}$ & 1,55 & 1,54 & 1,48 & 1,46 & 1,56 & 1,54 & 1,54 & 1,49 & 1,59 & 1,50 & 1,52 \\
\hline $\mathrm{Cs}$ & 2,2 & 2,7 & 1,2 & 1,3 & 2,3 & 1,3 & 1,8 & 1 & 1,8 & 2,2 & 2 \\
\hline $\mathrm{Rb}$ & 107,8 & 114 & 116 & 112,4 & 77,1 & 77,3 & 103,3 & 89,1 & 84,4 & 123,3 & 104,4 \\
\hline $\mathrm{Ba}$ & 1206 & 1154 & 1524 & 541 & 1248 & 1248 & 1220 & 1014 & 1130 & 1671 & 1359 \\
\hline $\mathrm{Th}$ & 14,9 & 13,9 & 2,4 & 56,5 & 5,7 & 6,9 & 10,6 & 2,6 & 12,5 & 21,8 & 8,2 \\
\hline $\mathrm{U}$ & 4,9 & 2,6 & 1 & 27,5 & 2,4 & 1,5 & 2,5 & 0,6 & 1,2 & 4,2 & 2 \\
\hline $\mathrm{Nb}$ & 2,1 & 2,7 & 0,6 & 0,6 & 2,3 & 0,9 & 2,5 & 1,7 & 2,2 & 2,8 & 3 \\
\hline $\mathrm{Ta}$ & 0,2 & 0,2 & 0,05 & 0,05 & 0,05 & 0,05 & 0,3 & 0,05 & 0,2 & 0,05 & 0,1 \\
\hline $\mathrm{La}$ & 37,8 & 37 & 6,2 & 31,2 & 13,7 & 14,5 & 18,2 & 6,7 & 39,9 & 27,9 & 18,8 \\
\hline $\mathrm{Ce}$ & 74,3 & 66,4 & 12,3 & 62,8 & 25,3 & 28,5 & 33,5 & 13,3 & 74,3 & 51,7 & 34,2 \\
\hline $\operatorname{Pr}$ & 7,2 & 6,91 & 1,12 & 6 & 2,67 & 2,67 & 3,5 & 1,26 & 7,33 & 5,24 & 3,52 \\
\hline $\mathrm{Sr}$ & 728,4 & 702,1 & 582 & 181,1 & 565,5 & 597,7 & 589,3 & 416,2 & 782,5 & 646,5 & 660,7 \\
\hline $\mathrm{Nd}$ & 23,1 & 24,3 & 3,6 & 19,2 & 9 & 9 & 12,2 & 4,2 & 25,8 & 17,6 & 13,2 \\
\hline $\mathrm{Sm}$ & 3,29 & 3,1 & 0,56 & 3,33 & 1,41 & 1,48 & 1,72 & 0,77 & 3,12 & 2,52 & 1,86 \\
\hline $\mathrm{Zr}$ & 147,3 & 150,9 & 52,2 & 84,6 & 104,6 & 86,2 & 92,2 & 71,5 & 144,6 & 111,8 & 118,2 \\
\hline $\mathrm{Hf}$ & 3,7 & 3,8 & 2,2 & 3,5 & 3 & 2,6 & 3,1 & 2,4 & 3,2 & 3,1 & 3,7 \\
\hline $\mathrm{Eu}$ & 0,92 & 0,87 & 0,48 & 0,48 & 0,54 & 0,5 & 0,63 & 0,46 & 0,82 & 0,91 & 0,86 \\
\hline $\mathrm{Gd}$ & 1,76 & 1,66 & 0,34 & 2,05 & 0,79 & 0,82 & 0,95 & 0,47 & 1,55 & 1,23 & 1,17 \\
\hline $\mathrm{Tb}$ & 0,2 & 0,2 & 0,04 & 0,26 & 0,1 & 0,1 & 0,14 & 0,05 & 0,19 & 0,15 & 0,13 \\
\hline Dy & 0,71 & 0,76 & 0,16 & 1,09 & 0,41 & 0,38 & 0,65 & 0,23 & 0,73 & 0,59 & 0,55 \\
\hline $\mathrm{Y}$ & 3 & 3,4 & 0,6 & 3,5 & 1,9 & 1,7 & 3,3 & 0,9 & 3 & 2,5 & 2,4 \\
\hline
\end{tabular}




\begin{tabular}{|c|c|c|c|c|c|c|c|c|c|c|c|}
$\mathrm{Ho}$ & 0,12 & 0,1 & 0,02 & 0,15 & 0,06 & 0,06 & 0,1 & 0,03 & 0,09 & 0,08 & 0,07 \\
\hline $\mathrm{Er}$ & 0,27 & 0,26 & 0,07 & 0,33 & 0,17 & 0,17 & 0,28 & 0,11 & 0,23 & 0,16 & 0,19 \\
\hline $\mathrm{Tm}$ & 0,04 & 0,04 & 0,01 & 0,05 & 0,03 & 0,03 & 0,05 & 0,02 & 0,03 & 0,03 & 0,03 \\
\hline $\mathrm{Yb}$ & 0,18 & 0,19 & 0,05 & 0,24 & 0,16 & 0,12 & 0,29 & 0,06 & 0,19 & 0,19 & 0,17 \\
\hline $\mathrm{Lu}$ & 0,03 & 0,03 & 0,01 & 0,05 & 0,03 & 0,02 & 0,05 & 0,01 & 0,03 & 0,03 & 0,03 \\
\hline
\end{tabular}

Apêndice 02: Continuação. 